DOI: $\underline{\text { https://doi.org/10.24867/05BE32Mitrovic }}$

\title{
FAZNO SPREGNUTA PETLJA I PROCENA NEURAVNOTEŽENOSTI MREŽE PRIMENOM VIŠEREZONANTNOG OPSERVERA
}

\section{MULTI-RESONANT OBSERVER PLL WITH ESTIMATION OF GRID UNBALANCES}

\author{
Aleksandra Mitrović, Fakultet tehničkih nauka, Novi Sad
}

\section{Oblast - ELEKTROTEHNIKA I RAČUNARSTVO}

Kratak sadržaj - U ovom radu je razmatran problem sinhronizacije na elektroenergetski sistem. Projektovan je PLL algoritam sa redukovanim estimatorom prostoperiodičnih poremećaja $i$ RST regulatorom. Implementacija upravljačkog algoritma je izvršena $u$ vremenski kontinualnom i diskretnom domenu.

Ključne reči: Sinhronizacija, PLL algoritam, Redukovani estimator prostoperiodičnih poremećaja, RST regulatori

Abstract - In this paper, phase locked loop or PLL algorithm for grid syncronization is investigated. The proposed technique is implemented with reduced order observer of prostoperiodic disturbances and RST controller. Algorithm control loop is implemented in continuous and discrete time domain.

Keywords: Grid syncronization, PLL algorithm, Reduced order observer, RST controller

\section{UVOD}

Sinhronizacija uređaja na elektroenergetski sistem je važna tema u oblasti elektroenergetike i generalno oblasti upravljanja sistemima. Uređaji koji se povezuju na elektroenergetski sistem mogu da predaju ili uzimaju energiju iz sistema $u$ zavisnosti od radnog režima u kome se nalaze (generatorski ili motorski) a povezuju se preko savremenih uređaja energetske elektronike.

Intuitivno se može zaključiti da je prilikom priključenja uređaja na električnu mrežu važno da postoji sinhronizacija između elektroenergetskog sistema i uređaja. Ukoliko uslovi sinhronizacije nisu ispunjeni javljaju se neželjeni efekti u vidu harmonika višeg reda koji se tretiraju kao poremećaji u sistemu i neophodno ih je eliminisati. Zbog toga se projektuje fazno spregnuta petlja ili PLL algoritam kojim se vrši sinhronizacija na mrežu. U literaturi postoje različite načini za realizicaiju PLL algoritma [1-3]

U okviru algoritma implementira se redukovani estimator (opserver) koji vrši procenu vrednosti nepoznatih poremećaja a potom se tako estimiran signal oduzima od merenog zašumljenog napona kako bi se dobila korisna komponenta signala. Ovakav signal se koristi u upravljačkom delu algoritma koji se implementira kao RST regulator.

\section{NAPOMENA:}

Ovaj rad proistekao je iz master rada čiji mentor je bila dr Mirna Kapetina, docent.

\section{ELEKTROENERGETSKI SISTEM I SINHRONIZACIJA SA ELEKTRIČNOM MREŽOM}

\subsection{Uopšteno o elektroenergetskom sistemu}

Elektroenergetski sistem obuhvata procese proizvodnje, prenosa i distribucije električne energije. Proizvodnja električne energije se vrši u elektranama (termoelektrane, hidroelektrane, nuklearne elektrane); prenos električne energije omogućava prenosna mreža (dalekovodi, kablovski vodovi, interkonektivni transformatori); distribucija je isporuka električne energije do korisnika (distributivne mreže, distributivni transformatori) [4].

Osnovni zadatak svakog elektroenergetskog sistema je da osigura kvalitetnu isporuku električne energije uz minimalne troškove.

\subsection{Uslovi sinhronizacije sa električnom mrežom}

Sinhronizacija je postupak kojim se uređaj dovodi u takvo radno stanje da se može priključiti na elektroenergetski sistem bez negativnih posledica. Da bi se izvršila sinhronizacija sa električnom mrežom neophodno je da se ispune sledeći uslovi: faze uređaja se moraju slagati sa fazama mreže, frekvencija uređaja mora biti jednaka frekvenciji mreže, naponi uređaja moraju biti jednaki naponima mreže i naponi uređaja moraju biti u fazi sa naponima mreže [5].

\subsection{Efekti sinhronizacije sa električnom mrežom}

Ukoliko neki od uslova sinhronizacije nije ispunjen dolazi do nepravilne sinhronizacije usled koje se mogu javiti velike struje izjednačavanja koje su uzrok poremećaja u mreži [5]. Ovakvi poremećaji se najčešće javljaju u vidu harmonika višeg reda. Harmonici se definišu kao neželjene spektralne komponente izobličenog signala čija je frekvencija jednaka celobrojnom umnošku osnovne frekvencije. Harmonici postoje u elektroenergetskom sistemu od početka primene naizmenične struje, međutim, njihov negativan uticaj dolazi do izražaja sa pojavom nelinearnih potrašača koji su danas brojniji u odnosu na linearne.

Shodno prethodno navedenim tvrdnjama, trofazni napon mreže u stacionarnom stanju se može predstaviti u sledećem obliku [1]:

$$
\begin{gathered}
u_{i}=U^{p} \cos \left(\omega_{0} t-k_{i} \frac{2 \pi}{3}+\varphi^{p}\right)+U^{n} \cos \left(-\omega_{0} t-\right. \\
\left.k_{i} \frac{2 \pi}{3}+\varphi^{n}\right)+\sum_{h} U_{i h} \cos \left(h \omega_{0} t-k_{i} \frac{2 \pi}{3}+\varphi_{i h}\right)
\end{gathered}
$$

gde je $h=1 \ldots n, k=0,1,-1$ i $i=a, b, c . U^{p}$ i $U^{n}$ su amplitude pozitivne $i$ negativne sekvence osnovne frekvencije napona mreže (FFPS i FFNS) dok su $\varphi^{p}$ i $\varphi^{n}$ njihove faze. $\omega_{0}$ je kružna učestanost napona mreže $\mathrm{i}$ 
iznosi $\omega_{0}=2 \cdot 50 \pi \mathrm{rad} / \mathrm{s}$. Treći sabirak u izrazu (2.1) predstavlja harmonike višeg reda koji se javljaju prilikom sihnronizacije pri čemu je $U_{i h}$ amplituda a $\varphi_{i h}$ faza h-tog harmonika.

Zbog jednostavnijeg zapisa, izraz (2.1) se može predstaviti u sledećoj formi:

$$
\underline{U}=\underline{U}_{1}+\sum_{h} \underline{U}_{h}
$$

gde je $\underline{U}$ fazor koji odgovara naponu $u$ i važi:

$$
\begin{aligned}
& \underline{U}_{1}=U^{p} e^{j \omega_{0} t}+U^{n} e^{-j\left(\omega_{0} t+\varphi_{n}\right)} \\
& \underline{U}_{h}=U_{h}^{p} e^{j\left(h \omega_{0} t+\varphi_{h}^{p}\right)}+U_{h}^{n} e^{-j\left(h \omega_{0} t+\varphi_{h}^{n}\right)}
\end{aligned}
$$

Kako bi se uprostio račun vrši se transformacija trofaznog stacionarnog sistema $(\mathrm{abc})$ u sinhrono rotirajući dvofazni sistem (dq) primenom Parkove transformacije. Ova transformacija, poznata i kao transformacija kretanja, primenjuje se kako bi se u ustaljenom stanju izbegla zavisnost kontrolisanih veličina od vremena a njena matrica transformacija je:

$$
\mathrm{D}=\left[\begin{array}{cc}
\cos \left(\theta_{g}\right) & \sin \left(\theta_{g}\right) \\
-\sin \left(\theta_{g}\right) & \cos \left(\theta_{g}\right)
\end{array}\right]
$$

Nakon primene matrice transformacije na (2.3) dobija se:

$\underline{U}^{d q}=\underline{U} e^{-j \omega_{0} t}=U^{p}+$

$U^{n} e^{-j\left(2 \omega_{0} t+\varphi_{n}\right)}+\sum_{h} U_{h}^{p} e^{\left[j(h-1) \omega_{0} t+\varphi_{h}^{p}\right]}+$

$U_{h}^{n} e^{\left[-j(h+1) \omega_{0} t+\varphi_{h}^{n}\right]}$

Kako je $\underline{U}^{d q}=U_{d}+j U_{q}$ sledi:

$u_{d}=U^{p}+U^{n} \cos \left(2 \omega_{0} t+\varphi_{n}\right)+\sum_{h} U_{h}^{p} \cos [(\mathrm{h}-$

1) $\left.\omega_{0} \mathrm{t}+\varphi_{h}^{p}\right]+U_{h}^{n} \cos \left[(\mathrm{h}+1) \omega_{0} \mathrm{t}+\varphi_{h}^{n}\right]+$

$$
\begin{gathered}
u_{q}=-U^{n} \sin \left(2 \omega_{0} t+\varphi_{n}\right)+\sum_{h} U_{h}^{p} \sin \left[(\mathrm{h}-1) \omega_{0} \mathrm{t}+\right. \\
\left.\varphi_{h}^{p}\right]-U_{h}^{n} \sin \left[(\mathrm{h}+1) \omega_{0} \mathrm{t}+\varphi_{h}^{n}\right]
\end{gathered}
$$

Motivacija za primenu Parkove transformacije je očigledna iz izraza (2.6). Ukoliko je napon mreže u ravnoteži i bez harmonika višeg reda onda važi $u_{d}=U^{p} \mathrm{i}$ $u_{q}=0$ [3].

\section{PLL ALGORITAM}

Algoritam fazno spregnute petlje ili PLL algoritam je jedan od najzastupljenijih algoritama sinhronizacije sa električnom mrežom.

Koncept PLL algoritma je poznat od početka 20. veka i ima primenu u mnogim tehničkim disciplinama. PLL struktura je otporna na poremećaje i nesimetriju i daje brzo i tačno podatak o faznom uglu napona mreže. Upravljačka petlja algoritma prikazan je na slici 1 .

PLL algoritam koristi detektor faze koji određuje razliku između faznog ugla ulazne veličine i estimiranog ugla. Dobijeni signal se filtrira i izlazni signal iz filtera pobuđuje naponski upravljan oscilator koji na svom izlazu generiše estimiranu vrednost faznog ugla koja prati fazni ugao ulazne veličine.

Za potrebe ovog rada posmatra se samo $q$ osa iz sinhrono rotirajućeg referentnog sistema što se može uočiti i na slici 1.

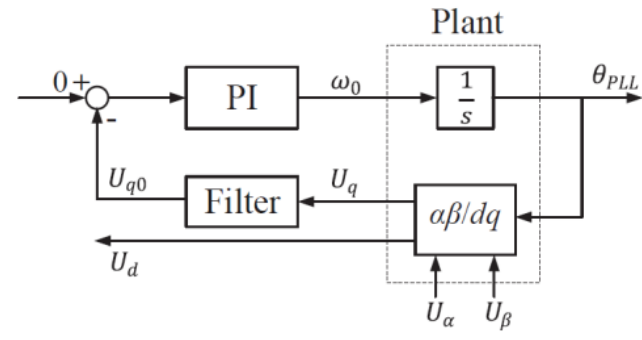

Slika 1. Upravljačka petlja PLL algoritma [3]

\section{PROJEKTOVANJE OPSERVERA REDUKOVANOG REDA}

Da bi se izvršila procena vrednosti poremećaja projektovan je estimator redukovanog reda u okviru PLL petlje. Estimatori (opserveri) su algoritmi koji omogućavaju procenu vrednosti nepoznate veličine od interesa na osnovu poznavanja ulaznih i izlaznih signala [6]. U slučaju estimatora redukovanog reda, kako bi se dodatno skratila procedura projektovanja opservera, vrši se podela promenljivih na direktno merljive i nepoznate veličine. Shodno tome, upravljačka petlja PLL algoritma sa ovako implementiranim estimatorom je prikazana na slici 2 [1]:

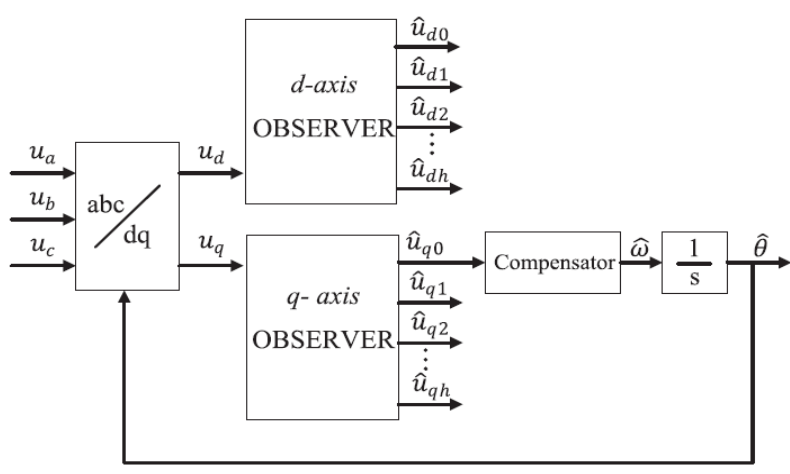

Slika 2. PLL algoritam sa estimatorom poremećaja [3]

\subsection{Vremenski kontinualni domen}

Transformisani napon $u_{q}$ je predstavljen izrazom (2.6). S obzirom da superpozicija bilo koja dva periodična signala iste frekvencije daje takođe periodični signal iste frekvencije, izraz (2.6) se može zapisati u sledećem obliku:

$u_{q}=u_{q 0}+\sum_{h} u_{q h}, u_{q h}=U_{q h m} \sin \left(\omega_{h} t-\varphi_{q h}\right)$

gde je $U_{q h m}$ amplituda a $\varphi_{q h}$ je faza h-tog harmonika u dq koordinatnom sistemu. Pošto se estimacija vrši tako što se oponaša (imitira) proces koji generiše veličinu od interesa [4], projektuje se linearni sistem sa impulsnim odzivom jednakim naponu $u_{q}[3]$ :

$\dot{u}_{q 0}=0, \quad \ddot{u}_{q h}+\omega_{h}^{2} u_{q h}=0$

Prva jednačina opisuje jednosmernu komponentnu signala dok druga opisuje harmonike višeg reda. $\mathrm{Na}$ osnovu navedenog matematičkog modela (4.2) može se izvršiti izbor promenljivih za $\mathrm{h}$ različitih harmonika:

$x_{1}=u_{q}, \quad x_{2 h}=u_{q h}, \quad x_{2 h+1}=\dot{u}_{q h}$

odnosno:

$\dot{x}_{1}=\sum_{h} x_{2 h+1}, \dot{x}_{2 h}=x_{2 h+1}, \dot{x}_{2 h+1}=-\omega_{h}^{2} x_{2 h}$ 
Nakon izbora promenljivih stanja vrši se projektovanje estimatora redukovanog reda. Promenljive stanja se dele $\mathrm{u}$ grupe direktno merljivih veličina $x_{1}$ i nepoznatih veličina koje se smeštaju u vektor $x_{2:}=\left[\begin{array}{llll}x_{2} & x_{3} & \ldots & x_{2 n+1}\end{array}\right]^{T}$ :

$\dot{x}_{1}(t)=A_{11} x_{1}(t)+A_{12} x_{2}(t)$

$\dot{x}_{2:}(t)=A_{21} x_{1}(t)+A_{22} x_{2}(t)$

gde je:

$A_{11}=0, A_{12}=\left[\begin{array}{lllll}0 & 1 & 0 & \ldots & 1\end{array}\right]_{2 n}, A_{21}=\left[\begin{array}{llll}0 & 0 & 0 & \ldots\end{array}\right]_{2 n}^{T} \mathrm{i}$

$A_{22}=\left[\begin{array}{ccccc}0 & 1 & 0 & 0 & \ldots \\ -\omega_{1}^{2} & 0 & 0 & 0 & \ldots \\ 0 & 0 & 0 & 1 & \ldots \\ 0 & 0 & -\omega_{2}^{2} & 0 & \ldots \\ \vdots & \vdots & \vdots & \vdots & \ddots\end{array}\right]$

Matematički model redukovanog estimatora je:

$\dot{z}=A_{0} z+G u_{q}, \quad \dot{\hat{x}}_{2:}=z+L u_{q}$

Matrica $L$ se naziva matrica pojačanja estimatora a parametarske matrice $A_{0}$ i $G$ se računaju na sledeći način:

$A_{0}=A_{22}-L A_{12}, \quad G=A_{21}-L A_{11}+A_{0} L$

Pogodnim izborom matrice $L$ svojstvene vrednosti matrice $A_{0}$ se smeštaju sa leve strane imaginarne ose u kompleksnoj ravni. Polovi estimatora se računaju na osnovu karakterističnog polinoma:

$f_{0}(s)=s^{2 n}+p_{2 n-1} s^{2 n-1}+\cdots+p_{1} s+p_{0}$

Matrica pojačanja estimatora $L$ se računa na sledeći način:

$f_{0}(s)=\operatorname{det}\left(s I-A_{22}+L A_{12}\right)$

Nakon izračunavanja matrice $L$ računaju se matrice $A_{0}$ i $G$. Na kraju se jednosmerna komponenta napona mreže dobija kao:

$\hat{u}_{q 0}=x_{1}-\sum_{h} \hat{x}_{2 h}$

Veličina $\hat{u}_{q 0}$ se koristi kao ulazni signal u regulacioni deo PLL petlje.

\subsection{Vremenski diskretni domen}

Transformisani napon $u_{q}$ se $\mathrm{u}$ diskretnom domenu može zapisati u sledećem obliku:

$u_{q}=u_{q 0}+\sum_{h} u_{q h} \quad, \quad u_{q h}=U_{q h m} \sin \left(\omega_{h} k T-\varphi_{q h}\right)=$

$=U_{q h m} \sin \left(\theta_{h} k-\varphi_{q h}\right)$

gde je $\theta_{h}=\omega_{h} T$ diskretna (digitalna) kružna učestanost a $T$ je perioda odabiranja.

Kao i u vremenski kontinualnom domenu, projektuje se linearni sistem koji ima impulsni odziv jednak naponu $u_{q}$ :

$u_{q h}(k+2)-2 \cos \left(\theta_{h}\right) u_{q h}(k+1)+u_{q h}(k)=0(4.12)$

$\mathrm{Na}$ osnovu matematičkog modela vrši se izbor promenljivih stanja:

$x_{1}=u_{q}(k), x_{2 h}=u_{q h}(k), x_{2 h+1}=u_{q h}(k+1)$

odnosno:

$x_{1}(k+1)=x_{1}(k)-\sum_{h} x_{2 h}(k)+\sum_{h} x_{2 h+1}(k)$,

$x_{2 h}(k+1)=x_{2 h+1}(k)$, $x_{2 h+1}(k+1)=-x_{2 h}(k)+2 \cos \left(\theta_{h}\right) x_{2 h+1}(k)$

Ovako definisane promenljive stanja se dele u grupu direktno merljivih veličina $x_{1}$ i grupu nepoznatih veličina koje se smeštaju u vektor $x_{2:}=\left[\begin{array}{llll}x_{2} & x_{3} & \ldots & x_{2 n+1}\end{array}\right]^{T}$ :

$x_{1}(k+1)=A_{11} x_{1}(k)+A_{12} x_{2}(k)$

$x_{2:}(k+1)=A_{21} x_{1}(k)+A_{22} x_{2}(k)$

gde je:

$A_{11}=1, A_{12}=\left[\begin{array}{llll}-1 & 1 & -1 \ldots 1\end{array}\right]_{2 n}, A_{21}=\left[\begin{array}{lll}0 & 0 & 0\end{array}\right]_{2 n}^{T} \mathrm{i}$

$A_{22}=\left[\begin{array}{ccccc}0 & 1 & 0 & 0 & \ldots \\ -1 & 2 \cos \left(\theta_{1}\right) & 0 & 0 & \ldots \\ 0 & 0 & 0 & 1 & \ldots \\ 0 & 0 & -1 & 2 \cos \left(\theta_{2}\right) & \ldots \\ \vdots & \vdots & \vdots & \vdots & \ddots\end{array}\right]$

Sva preostala izvođenja vezana za matematički model redukovanog estimatora, određivanje matrica $L, A_{0}$ i $G$ i napona $\hat{u}_{q 0}$ su identična kao $\mathrm{u}$ vremenski kontinualnom domenu, jednačine (4.6) - (4.10).

\section{PROJEKTOVANJE REGULACIONOG DELA ALGORITMA U VIDU RST REGULATORA}

RST regulatori predstavljaju strukturu koja je proširenje serije klasičnih regulatora jer se uvodi dodatni stepen slobode koji omogućava dizajneru da odredi ponašanje sistema u zatvorenoj povratnoj petlji na različite signale reference $i$ poremećaja. $U$ strukturi klasičnog RST regulatora postoje dva stepena slobode, komponenta direktnog upravljanja i komponenta upravljanja $u$ povratnoj grani. Struktura RST regulatora je prikazana na slici 3:

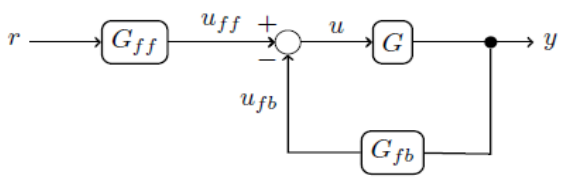

Slika 3. RST regulator

gde je funkcija prenosa procesa $G(s)=\frac{B(s)}{A(s)}, G_{f f}(s)=\frac{T(s)}{R(s)}$ je komponenta upravljanja u direktnoj grani a $G_{f b}(s)=$ $\frac{S(s)}{R(s)}$ je komponenta upravljanja u povratnoj grani.

\subsection{Vremenski kontinualni domen}

Upravljački signal na osnovu slike 3 je oblika:

$u(t)=-u_{f b}(t)+u_{f f}(t)$

Primenom Laplasove transformacije na izraz (5.1) i uvrštavanjem izraza za $G_{f f}(s)$ i $G_{f b}(s)$ dobija se tipična struktura RST regulatora u kompleksnom domenu:

$R U(s)=-S Y(s)+T R(s)$

pa se na osnovu ovoga mogu dobiti izrazi za funkciju spregnutog prenosa i karakteristični polinom:

$G_{c l}(s)=\frac{B T}{A R+B S}, \quad f_{c l}(s)=A R+B S$

$R$ i $S$ su polinomi koji se računaju na sledeći način:

$R=s f_{0}(s) R_{1}(s), \quad S=k_{0} \prod_{h}\left(s^{2}+\omega_{h}^{2}\right) S_{1}(s)$ 
pri čemu je $k_{0}=\frac{p_{0}}{\prod_{h} \omega_{h}^{2}}$ pojačanje estimatora i računa se iz uslova da je ukupno statičko pojačanje jednako nuli. Takođe, funkcija prenosa estimatora je:

$G_{0}(s)=\frac{U_{q 0}(s)}{U_{q}(s)}=k_{0} \frac{\prod_{h}\left(s^{2}+\omega_{h}^{2}\right)}{f_{0}(s)}$

$\mathrm{Na}$ osnovu navedenog može se formirati karakteristični polinom celokupnog sistema na osnovu koga se određuju nepoznati parametri:

$f_{c}(s)=s^{2} f_{0}(s) R_{1}(s)+k_{0} k_{T} S_{1}(s) \prod_{h}\left(s^{2}+\omega_{h}^{2}\right)$

pri čemu je $k_{T}$ pojačanje dq transformacije nakon linearizacije. Da bi prethodna jednačina bila rešiva neophodno je da broj promenljivih bude jednak stepenu sistema pa sledi:

$R_{1}(s)=1, \quad S_{1}(s)=k_{p}(s+\sigma)$

Nepoznati parametri se dobijaju metodom podešavanja polova. Prvo je potrebno definisati željeni karakteristični polinom koga određuju polovi koji definišu ponašanje sistema a potom se koeficijenti tako definisanog polinoma izjednačavaju sa koeficijentima iz $f_{c}(s)$.

\subsection{Vremenski diskretni domen}

Sva izvođenja i postupak određivanja nepoznatih parametara navedeni u vremenski kontinualnom domenu važe i u vremenski diskretnom domenu. Shodno tome, u nastavku će biti samo navedeni krajnji izrazi od interesa.

Funkcija prenosa estimatora u diskretnom domenu je:

$G_{0}(z)=\frac{U_{q 0}(z)}{U_{q}(z)}=k_{0} \frac{\prod_{h}\left(z^{2}-2 z \cos \left(\theta_{h}\right)+1\right)}{f_{0}(z)}$

gde je pojačanje estimatora $k_{0}=\frac{p_{0}}{\prod_{h}\left(2-2 \cos \left(\theta_{h}\right)\right)}$, karakteristični polinom estimatora je $f_{0}(z)=\operatorname{det}(z I-$ $\left.A_{22}+L A_{12}\right) \quad$ a karakteristični polinom celokupnog sistema je:

$f_{c}(z)=(z-1)^{2} f_{0}(z) R_{1}(z)+$

$+k_{0} k_{T} S_{1}(z) \prod_{h}\left(z^{2}-2 z \cos \left(\theta_{h}\right)+1\right)$

pri čemu je $R_{1}(z)=1$ i $S_{1}(z)=k_{p}(z+\sigma)$.

\section{EKSPERIMENTALNI REZULTATI}

Predloženi PLL algoritam primenjen je da bi se kroz simulacije testirala sinhornizacija mreže uz prisustvo viših harmonika u naponu mreže.

Razmatra se slučaj kada postoje dva poremećaja na frekvencijama $\omega_{1}=2 \omega_{0}$ i $\omega_{2}=3 \omega_{0}$ gde je $\omega_{0}=2$. $50 \pi \mathrm{rad} / \mathrm{s}$. Dominantni polovi RST regulatora u PLL algoritmu se biraju tako da imaju prirodnu neprigušenu učestanost $\omega_{0}$ i relativni koeficijent prigušenja $\xi=0.7$ dok se ostali polovi nalaza dalje od imaginarne ose. Opisan algoritam je testiran i u vremenski kontinualnom i diskretnom domenu kada se primenjuje perioda odabiranja je $T_{s}=\frac{2 \pi}{\omega_{s}}$ gde je $\omega_{s}=5 \omega_{2}$. Dobijen rezultati su prikazani na likama 4 i 5 . Sa slike 4 se jasno vidi da je algoritam realizovan $\mathrm{u}$ kontinualnom domenu uspešno izdvojio iz ,zagađenog", signala osnovni harmonik na frekveniciji $\omega_{0}=2 \cdot 50 \pi \mathrm{rad} / \mathrm{s}$, a slika 5 prikazuje rezultate simulacije predloženog algoritma realizovanog $\mathrm{u}$ diskretnom domenu.

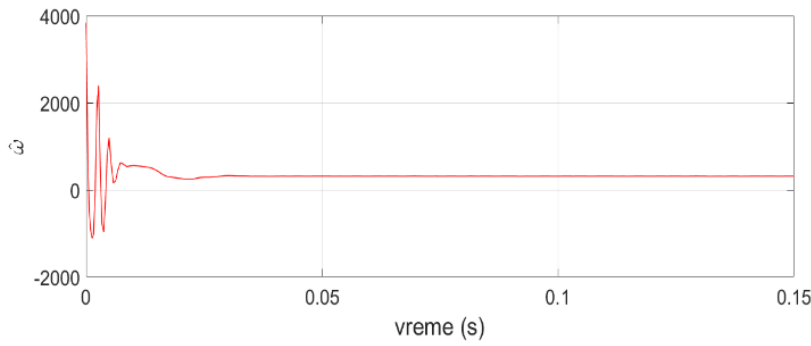

Slika 4. Estimirana kružna učestanost napona mreže

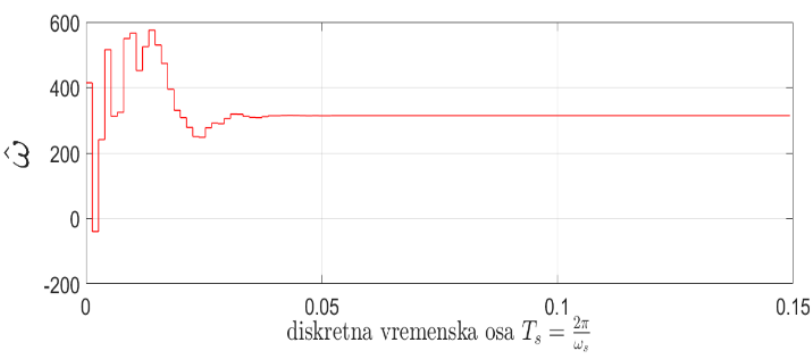

Slika 5. Estimirana kružna učestanost napona mreže

\section{LITERATURA}

[1] M. Vekić, M. R. Rapaić, T. B. Šekara, S. Grabić, E. Adžić, "Multi-resonant observe PLL with real-time estimation of grid unbalances", International Journal of Electrical Power \& Energy Systems, Vol. 108, pages 52-60, June 2019.

[2] H. Awad, J. Svensson and M. J. Bollen, "Tuning software phase-locked loop for series-connected converters, " in IEEE Transactions on Power Delivery, vol. 20, no. 1, pp. 300-308, Jan. 2005. doi: 10.1109/TPWRD.2004.837823

[3] W. Li, X. Ruan, C. Bao, D. Pan and X. Wang, "Grid Synchronization Systems of Three-Phase GridConnected Power Converters: A Complex-VectorFilter Perspective," in IEEE Transactions on Industrial Electronics, vol. 61, no. 4, pp. 1855-1870, April 2014.

[4] S. Branković, "Električne mreže i dalekovodi", Zavod za udžbenike i nastavna sredstva, Beograd, 1996.

[5] M. Božić, M. Rosić, M. Bjekić, "Vizuelizacija postupka sinhronizacije sinhronog generatora na mrežu", 6. Međunarodni simpozijum, Tehnički fakultet Čačak, 3-5. Jun 2011.

[6] M. R. Rapaić, Z. D. Jeličić, "Projektovanje linearnih regulatora i estimatora u prostoru stanja”, Univerzitet u Novom Sadu, Fakultet tehničkih nauka, 2014.

\section{Kratka biografija}

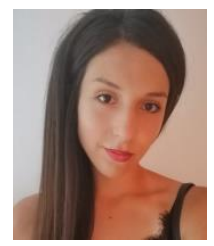

Aleksandra Mitrović rođena je u Zvorniku 1995. god. Master rad na Fakultetu tehničkih nauka iz oblasti Elektrotehnike i računarstva - Adaptivno i napredno upravljanje odbranila je 2019.god.

Kontakt: ana.mitroviczv@gmail.com 